\title{
O repórter Euclides da Cunha em Canudos'
}

\author{
Antonio Carlos Hohlfeldt
}

\section{Sobre $\bullet$ autor}

Possui graduação em Letras pela Universidade Federal do Rio Grande do Sul (1973), mestrado em Lingüística e Letras pela Pontifícia Universidade Católica do Rio Grande do Sul

(1991) e doutorado em Lingüistica e Letras pela Pontifícia Universidade Católica do Rio Grande do Sul (1998). Atualmente é professor de "Teorias da comunicação"

e "Leituras em Jornalismo" na Pontifícia Universidade Católica do Rio Grande do Sul hohlfeld@pucrs.br

\section{The journalist Euclides da Cunha in Canudos}

\section{Abstract}

The paper works about a context of Euclides da Cunha's time. It is a study about the charasteristics of newsmaking at the end of XIX century and beginning of the XXth., specialy the Canudos campaign and how it was received and perceived by the press. Canudos has received a great attention from the press and became the first midiatic event in the brazilian history. At the end, there is a study about the original texts of Cunha sent from the warfront. These texts show values, questions and practices that remain important in contemporary journalism.

\section{Key words:}

Journalism history, Journalism theory, War's reporting, Euclides da Cunha, Canudos 
"Quem volta da região assustadora

De onde eu venho, revendo inda na mente Muitas cenas do drama comovente (...)" Euclides da Cunha, em "Página vazia", 14.10.1897

Em texto recente, que faz a revisão da historiografia brasileira, Jacqueline Hermann afirma que "Canudos foi, seguramente, o movimento de religiosidade popular mais estudado entre todos os inúmeros exemplos já conhecidos no Brasil" (HERMANN in FERREIRA; DELGADO,2006, p. 138).

Do mesmo modo, estudiosos do fenômeno midiático no país destacam que "a Guerra de Canudos foi, no Brasil, o acontecimento jornalístico mais importante do ano de 1897"(SARMATZ, 1995). Walnice Nogueira Galvão, que mapeou toda a cobertura dada ao evento, chega a registrar que, "a esta altura, o assunto é tão candente que 'Sobre Canudos' torna-se seção e passa a sair com regularidade [no jornal O País]"(GALVÃO, 1994, p. 59).

$\mathrm{O}$ que significava exatamente os acontecimentos de Canudos e como a imprensa os via, é o que nos interessa aqui, para compreendermos e valorizarmos a função do repórter Euclides da Cunha, enviado por Júlio Mesquita, em nome de O Estado de São Paulo, para o acompanhamento do que viria a ser a derrocada de Canudos.

\section{Canudos e Antonio Conselheiro}

Antonio Vicente Mendes Maciel nasceu em Quixeramobim, estado do Ceará, segundo alguns em 1828, segundo outros em 1830. Casou-se em 1857, mas foi traído pela mulher, que fugiu com um militar, é preso em 1877 acusado de matar a esposa e a mãe, mas é solto por falta de provas. Desde pouco antes, por volta de 1870, aos 42 anos de idade, começa a preocupar as autoridades eclesiásticas, pois começa a percorrer os sertões auto-denominando-se enviado de Deus. Em 1877 começa a inquietar também as autoridades civis, pois opõe-se claramente a algumas das medidas adotadas pela República. Em 1895 chega a Vaza-Barris, fazenda abandonada, que ocupa com alguns seguidores, já agora com 65 anos de idade. Belo Monte transforma-se rapidamente, preocupando o Governador Luís Viana. Mas os acontecimentos vão se precipitar, conforme nos narra o próprio Euclides da Cunha, em outubro de 1896, quando Antonio Conselheiro encomenda e paga - adiantada - madeira para construir uma capela no arraial, madeira que não lhe é entregue. Isso desencadeia um primeiro choque dos seguidores de Maciel. Intrigas políticas provocam o Governador a enviar contra ele uma tropa.

Seguem-se as campanhas conhecidas: em 1896, um contingente policial segue sob o comendo do Tenente Manuel de Silva Pires Ferreira com 3 oficiais e 113 praças, além de dois guias,

${ }^{1}$ Versão preliminar foi apresentada na mesa redonda "O centenário de Euclides da Cunha A epopéia de Canudos", organizada pela Profa. Dra. Maria Regina Barcelos Bettiol, para a Livraria Cultura de Porto Alegre, no dia 27 de abril de 2009. 
sendo logo dizimado. No mesmo ano, um segundo ataque é desferido, agora sob o comando do Major Febrônio de Britto, contando 10 oficiais, canhões, uma metralhadora e cerca de 600 homens, igualmente derrotados.

Já no âmbito do Exército, uma terceira campanha é desenvolvida em março de 1897, sob o comando do Coronel Antonio Moreira César, com mais de 1300 homens, 6 canhões e forte aparato bélico. Mas o coronel morre em combate, logo nos primeiros dias, e a força retroage. Esse acontecimento vai provocar comoção em todo o país. Em Salvador e no Rio de Janeiro, jornais monarquistas são atacados e depredados, pois entende-se que os agora já denominados "rebeldes" de Canudos estão vinculados aos monarquistas.

É de 14 de março de 1897 o primeiro artigo que toca no tema, de autoria de Euclides da Cunha. Ele comenta o envio das tropas comandadas por Moreira César, num texto intitulado "A nossa Vendéia"(CUNHA, 1897). O título aludia a acontecimento histórico do século XVIII, em que camponeses da região da Vendéia (Vendée), na França, rebelaram-se contra decisões do governo revolucionário que executara o rei, laicizara o Estado e vinha estabelecendo cobrança de impostos e recrutamento militar que desagradava aos camponeses. Jean Nicolas Stofflet e Jacques Cathelineau foram seus líderes. A rebeldia, entre 1793 e 1796, foi combatida fortemente pelo governo revolucionário, mas movimentos de rebeldia continuaram até por volta de 1800 . Cerca de 15 mil pessoas foram mortas na ocasião.

Depois de descrever geologicamente a região baiana, Euclides da Cunha escreve:

É sobre estes tabuleiros, recortados por inúmeros vales de erosão, que se agitam nos tempos de paz e duas estações de águas, na azáfama ruidosa e álacre das vaquejadas, os rudes sertanejos completamente vestidos de couro curtido - das amplas perneiras ao chapéu de abas largas - tendo a tiracolo o laço ligeiro a que não escapa o garrote mais arisco ou rês alevantada, e pendente, à cinta, a comprida faca de arrasto, com que investe e rompe intricados cipoais.

Após a derrota da tropa de Moreira César, a 3 de março de 1897, Euclides da Cunha voltou ao assunto, em artigo publicado no dia 17 de julho de 1897, sob o mesmo título (CUNHA, 1897). O artigo, bem mais longo, é também muito crítico em relação às ações do governo. "A profunda estratégia européia naquelas paragens desconhecidas é abalada por uma tática rudimentar pior que a tática russa do deserto", analisa ele, identificando o movimento de guerrilha que caracterizaria os ataques dos rebeldes. Repetindo a descrição do tipo físico do sertanejo, ele acrescenta, enquanto interpretação:
É de 14 de março de 1897 o primeiro artigo que toca no tema, de autoria de Euclides da Cunha. Ele comenta

o envio das tropas comandadas por

Moreira César, num texto intitulado "A nossa Vendéia" 
O jagunço é uma tradição justalinear quase do iluminado da Idade Média. O mesmo desprendimento pela vida, a mesma indiferença pela morte, dão ao mesmo heroísmo mórbido e inconsciente de hipnotizado e impulsivo. Uma sobriedade extraordinária garante-lhe a existência no meio das maiores misérias.

Defendendo o valor dos soldados que então haviam sido derrotados, valoriza a saída das novas tropas, a chamada Quarta Expedição, agora sob o comando do General Artur Oscar de Andrade Guimarães, com cerca de vinte mil homens e o armamento mais moderno posto à disposição do Exército. O próprio Ministro da Guerra, Marechal Machado Bittencourt, acompanha a tropa, e é como tenente reformado, que Euclides da Cunha acaba seguindo neste grupo, adido do Estado Maior do Ministro. Ainda desconhecendo que virá a integrar esta tropa, contudo, ele antecipa:

As tropas da República seguem lentamente, mas com segurança, para a vitória. Fora um absurdo exigir-lhes mais presteza (...) Amanhã, quando forem desbaratadas as hostes fanáticas do Conselheiro e descer a primitiva quietude aos sertões baianos, ninguém conseguirá perceber, talvez, através das matas impenetráveis, coleando pelo fundo dos vales (...) os soldados da República.

Euclides da Cunha colocava-se claramente contrário aos rebeldes e em favor da República como na valorização da tropa. Logo se verá, contudo, que as observações de campo, bem como sua absoluta honestidade intelectual (OLIVEIRA, 1983, p. 77) vão-no levar a profundas modificações na avaliação que fará do movimento.

A luta será rápida mas profundamente violenta. Saindo em agosto de 1897, para a cobertura dos acontecimentos, já no dia 22 de setembro de 1897 Euclides da Cunha pode documentar a morte de Antonio Conselheiro. Cerca de 5 mil casebres, abrigando mais de 25 mil pessoas, são absolutamente destruídos pelas tropas militares, quando, no dia 5 de outubro de 1897 os últimos resistentes são mortos e a vitória alcançada. Evidentemente, Euclides da Cunha não viu tudo o que aconteceu, até porque, depois do deslocamento do Rio de Janeiro, permaneceu 24 dias em Salvador, à espera do deslocamento para o interior (RABELLO, 1983, p. 82). Mas soube ver e tratou de compreender, transmutando o "preconceito inicial", na expressão de Wilson Martins (1977, Vol. V, p. 6), de um "republicano convicto" (MOURA, 1964, p.51) num verdadeiro grito de horror e numa forte denúncia do abandono em que viviam e ainda hoje vivem nossas populações interioranas, de que as mudanças de avaliação, ocorridas entre os textos jornalísticos e a versão final do livro bem atestam.
Euclides da Cunha colocavase claramente contrário aos rebeldes e em favor da República como na valorização da tropa. Logo se verá, contudo, que as observações de campo, bem como sua absoluta honestidade intelectual vão-no levar a profundas modificações na avaliação que fará do movimento. 


\section{Colaboração de Euclides na imprensa}

"O jornal era o mais eficiente veículo de comunicação de massa no Brasil do final do século [XIX]", avalia Walnice Nogueira Galvão (1994, ps. 5 e 6). A variedade dos escritos é surpreendente para um leitor atual, mas levando-se em conta que, proporcionalmente, haveria mais jornais naquela época que nos dias de hoje, sobretudo devido às disputas então travadas em torno das ideologias republicanas e monárquicas, deve-se lembrar que a maioria desses jornais - pasquins, tão somente, alguns, agressivos e mal redigidos - tinham vida efêmera, ou porque eram empastelados ou porque seus responsáveis arrefeciam seus ardores tão logo enfrentassem as autoridades. Se em São Paulo destacavam-se $O$ Estado de São Paulo, o Correio Paulistano (futura Folha de São Paulo) e O Comércio de São Paulo, o Rio de Janeiro, como capital da república, multiplicava suas publicações, como o Jornal do Brasil, A Notícia, O País, O Jornal do Comércio, A Gazeta de Notícias, o República, a Folha da Tarde, e assim por diante.

Visualmente, eram jornais pesados, pois ainda inexistia a ilustração. Assim, apresentavam-se com colunas estreitas, quase sempre em número de oito, já que a maioria absoluta dos jornais era standart, paginados de alto a baixo. "Mas a monotonia é apenas visual", alerta Walnice Nogueira Galvão, que acrescenta:

A leitura desses jornais é fascinante (...) O jornal dessa época acolhe em suas páginas material variadíssimo e que hoje se encontra disperso pelos outros veículos. É ao mesmo tempo um jornal mais literário e menos literário. Mais, porque nele são freqüentes os contos, os poemas, as crônicas, e porque nele escreveram regularmente grandes nomes da criação literária(...) e menos: o estilo jornalístico, ainda muito pouco desenvolvido, peca a todo o momento pela incorreção da linguagem (...) o jornal era um mosaico constituído por fragmentos de natureza vincadamente díspar (...) suscita no leitor de hoje a opinião de que tudo, mas tudo, se passa nas páginas dele. E não só se passa como se cria, sejam incidentes, intrigas ou até mesmo conspirações (GALVÃO, 1994, ps. 17 e 18).

Canudos vai-se tornar notícia de jornal sobretudo a partir da derrota de Moreira César. E as fontes não eram apenas correspondentes regionais dos periódicos ou enviados especiais, o que vai ocorrer apenas na etapa final da luta. As fontes eram, em sua grande maioria, os próprios militares que lá estavam e que, escrevendo para as suas famílias, avaliavam bem a necessidade de manter informada a opinião pública e pediam que as mesmas fossem levadas até as redações. Temos, pois que, fundamentalmente, o que o leitor conhecia da rebeldia sertaneja era uma versão, se não oficial, ao menos oficiosa da luta, porque suas fontes estavam sempre do lado dos republicanos. Isso não significa que
Canudos vai-se tornar notícia de jornal sobretudo a partir da derrota de Moreira César. Inicialmente, as fontes eram, em sua grande maioria, os próprios militares que lá estavam e que, escrevendo para as suas famílias, avaliavam bem a necessidade de manter informada a opinião pública e pediam que as mesmas fossem levadas até as redações 
algum jornalista enviado ao campo de batalha não enfrentasse perigos e até encontrasse a morte. Foi o caso de Francisco de Paula Cisneiros Cavalcanti, que escrevia para A Notícia. Ele veio a falecer em 18 de julho, em combate, porque a maioria desses correspondentes acabava viajando na condição de militar, como vai ocorrer, aliás, com o próprio Euclides da Cunha, só que, neste caso, ele já se encontrava reformado. Cisneiros era Alferes, assim como Manuel Benício, que escrevia para o carioca Jornal do Comércio, era capitão (MARTINS, 1997, p. XII).

A derrota de Moreira César provoca a curiosidade dos jornais, que por seu lado refletem a curiosidade do leitor. Assim, um levantamento sumário de Walnice Nogueira Galvão destaca alguns dos correspondentes então enviados ao cenário da guerra: a $G a$ zeta de Notícias enviou Júlio Procópio Favila Nunes, gaúcho, que já cobrira a Revolta da Armada; O Estado de São Paulo escolheu Euclides da Cunha; o Jornal do Commmercio, do Rio de Janeiro, o pernambucano Manuel Benício; o sergipano Siqueira de Menezes, tenente-coronel, escreve para $O$ Pais, sob o pseudônimo de Hoche; Lélis Piedade escreve para o Jornal de Notícias, de Salvador, além de Manuel de Figueiredo, Alfredo Silva e muitos outros, nem sempre identificados pelas respectivas redações.

Sabe-se que Manuel Benício foi mandado embora, por ter transmitido informações consideradas impróprias pelo Exército (GALVÃO, 1994, p. 112), sendo substituído por um outro profissional. A cobertura por ele efetuada, de certo modo, é complementar à de Euclides da Cunha, porque ele cobre o período de 1. a 24 de julho de 1897, o que faz supor que ele permaneceu entre 24 de junho até setembro daquele ano. Euclides da Cunha, por seu lado, chega a Queimadas em 31 de agosto do mesmo ano, e a Canudos apenas em 15 de setembro, portanto, vinte dias antes da destruição da cidade (MARTINS, 1997, p. XVII).

Há enormes dificuldades para se enviar o material, quer por causa da censura militar, quer por causa da distância entre Monte Santo e Queimadas e depois a chegada a Salvador para dali ser retransmitido às bases dos jornais, em São Paulo ou Rio de Janeiro. Daí a importância das referências que $O$ Estado de São Paulo apõe a cada artigo publicado, indicando sempre a data de procedência do texto. Por exemplo, o primeiro artigo enviado por Euclides da Cunha é editado em 18 de agosto, mas fora enviado ainda a 10 de julho, portanto, mais de um mês antes! Às vezes, um artigo posterior é publicado antes, como ocorre em 23 de agosto com texto enviado no dia 7 de agosto, para no dia seguinte, 24, divulgar-se texto enviado no dia 12 de julho.

Walnice Nogueira Galvão reconhece que "a Guerra de Canudos, se não inaugurou, deve ter intensificado extraordinariamente no Brasil a praxe jornalística de dispor enviados especiais no local dos acontecimentos" (1994, p. 109). Vale a avaliação de Marcelo Bulhões: 
A irrupção da reportagem na história do jornalismo, ocorrida no século XIX, se faz com a evidência a um aspecto que a acompanharia desde então, tornando-se um traço essencial do gênero: a necessidade do jornalista - o repórter - no palco das ações dos acontecimentos, trazendo a voz de quem convive estreitamente com os fatos (...) Daí dizer-se que a reportagem é o ambiente mais inventivo da textualidade informativa (BULHÕES, 2007, p. 45).

No caso, especialmente O Estado de São Paulo, a Gazeta de Notícias, A Notícia e o Jornal do Commmercio - os três últimos do Rio de Janeiro, destacaram-se em tal tarefa.

\section{Euclides enquanto repórter}

Euclides da Cunha não se acomodava muito à profissão de engenheiro (RABELLO, 1983, p. 87). Sentia-se, na verdade, mais atraído pelo jornalismo. Alguns autores, como Franklin de Oliveira, identificam diferentes fases em seu pensamento. Assim, pode-se falar de um primeiro período, que vai de sua formação enquanto engenheiro até o início da Campanha Civilista, ou seja, entre 1884 e 1892; um segundo momento, durante a Campanha, onde ele se encontra num quase-exílio no sul de Minas Gerais, e que vai até 1895; e um terceiro, a partir deste momento, quando ele se encontra já trabalhando enquanto engenheiro, de volta a São Paulo, e inicia suas colaborações para o jornal $O$ Estado de São Paulo (OLIVEIRA, 1983, p. 37). Quando o jornal o envia para os sertões baianos, "Euclides não tinha senão uma intuição muito rarefeita da realidade brasileira" (OLIVEIRA, 1983, p. 47).

Clóvis Moura prefere falar em quatro fases, assim identificadas: a) da formação na Escola Militar à viagem à Bahia, com a predominância do positivismo comtiano; da viagem a Salvador até sua chegada a Canudos, quando assume uma posição crítica à ortodoxia republicana; uma terceira fase, de seu regresso de Belo Monte, até o lançamento de Os sertões, em 1902, quando busca basear-se nas teorias então em voga para bem explicar os acontecimentos a que assistira, mas onde remanesce certo racismo em torno dos sertanejos; e, enfim, uma quarta fase, desde esse momento a seu concurso acadêmico, quando revisa suas posições teóricas e aprofunda a interpretação da realidade brasileira que tentava entender (1964, p. 18).

Nicolau Sevcenko, estudando o conjunto de produção euclidiana, por seu lado, identifica a multiplicidade de gêneros, que vão da historiografia à geografia, passando pela crônica, a epistolografia e a poesia (SEVCENKO, 1983, p. 134). Curiosamente, o crítico não menciona o jornalismo, a não ser que aquela referência à crônica signifique tal campo. No entanto, deve-se destacar o jornalismo euclidiano que, por seu lado, dividir-se-ia, este sim,
Apesar de colaborar com textos de outros gêneros para os jornais (historiografia, poesia) devese destacar - jornalismo euclidiano que dividir-se-ia entre a crônica e

a reportagem 
entre a crônica e a reportagem. No caso da crônica, poderíamos integrar o significativo número de artigos que ele publicara antes de viajar para a Bahia e que voltaria a divulgar, quando de sua volta. Na reportagem, caberia especialmente o conjunto dos textos enviados desde Canudos, mas também outras séries produzidas, por exemplo, quando de sua ida ao norte do país.

O próprio Sevcenko registra o fato de Euclides da Cunha ter dirigido um jornal socialista em São José do Rio Pardo, chamado $O$ proletário (SEVCENKO, 1983, p. 151). Sua estréia em O Estado de São Paulo ocorreu em 22 de dezembro de 1888, quando comenta a transferência de Deodoro da Fonseca para o sul de Mato Grosso, suspeito de atividades políticas (ANDRADE, 2002, p. 49). Uma semana depois, divulgaria novo artigo, sob o título "Revolucionários", em que defende ser o homem "filho de sua região" e de seu tempo. Nove dias mais tarde, um terceiro artigo pode ser lido, iniciando a série de artigos chamada "Atos e palavras", em que analisava o contexto político do momento, sob o pseudônimo de Proudhon. Tem 22 anos de idade, e sonha com a república. No dia 24 escrevia o último artigo da série e se preparava para retornar ao Rio de Janeiro, intentando cursar a Escola Politécnica, de que desiste, aparentemente por falta de meios para financiar os estudos.

Do Rio de Janeiro, continua enviando artigos para o jornal paulista, ao longo dos meses de maio e junho de 1889. Depois da república, distancia-se um pouco do jornalismo, mas retorna, em 4 de março de 1897, para escrever sobre a distribuição dos vegetais no estado paulista - tema, portanto, mais diretamente vinculado às suas atividades profissionais do que a sua eventual militância política. Dez dias mais tarde, contudo, já conhecida a derrota de Moreira César, edita o primeiro texto de "A nossa Vendéia”, a 14 de março, o que vai lhe valer, logo depois, o convite para a viagem.

Andrade afirma que o jornal A Província de São Paulo "era um jornal vivo e atuante, cujas páginas ensinam muito daquele tempo que adorava o folhetim e era familiar à polêmica" (ANDRADE, 2002, p. 49). José Marques de Melo e Adolpho Queiroz mostram que o jornal tinha significativa tiragem para a época. Francisco Rangel Pestana e Américo Brasiliense fundaram o jornal a 4 de janeiro de 1875, com quatro páginas, das quais uma e meia era ocupada por publicidade, sendo propriedade da empresa Pestana, Campos \& Cia., formada por mais de quinze republicanos paulistas e administrado por José Maria Lisboa (MELO; QUEIROZ, 1998, p. 163). Para a sua impressão, usava um prelo Alouzet movido a mão, para o que recrutara alguns negros livres. Era uma tarefa tão difícil que a primeira edição circulou com três dias de atraso. O jornal, embora claramente republicano, apenas a partir de 1884 assumiria explicitamente sua ideologia,

${ }^{2}$ Destaque-se que, neste momento, o jornais ainda se chama A Província de São Paulo, pois estamos ainda ao tempo do império. 
depois de já firmado financeiramente, quando troca de propriedade e passa a ser editado pela empresa Alberto Salles \& Cia. Salles, contudo, retirou-se no ano seguinte, diante da stuação financeira precária do jornal. Naquele ano, entra para o jornal Júlio Mesquita, que assume a direção do mesmo em 1891, quando Rangel Pestana se elege para o senado. A Província de São Paulo participou ativamente da campanha republicana e logo após a proclamação da república, troca seu nome para $O$ Estado de São Paulo. Foi o primeiro diário a ser vendido nas ruas da cidade, a partir de 23 de janeiro de 1876.

Em 1897, foi pioneiro na decisão de enviar um correspondente à Bahia para acompanhar os acontecimentos de Canudos. Júlio Mesquita tornar-se-ia proprietário do jornal em 1902, dentre outros motivos, justamente por esta perspectiva mais aberta que evidenciava em relação ao jornalismo: tratava-se, como registra Sylvio Rabello, "de uma inovação nos métodos do jornalismo: a reportagem colhida ao vivo" partindo a 4 de agosto para Salvador (RABELLO, 1983, p. 90). O pesquisador acompanha a viagem, desconfortável, a bordo do navio "Espírito Santo", a permanência de 24 dias na capital baiana; e, enfim, sua partida, a 30 de agosto, acompanhando o Ministro da Guerra. Para isso, teve de pedir licença especial para afastar-se de seu trabalho, o que lhe foi dada (ANDRADE, 2002, p. 130).

Se o correspondente achava-se insatisfeito com a situação, não deixava de cumprir com suas obrigações, e bem. Verifica-se que ele enviou artigos variados ao longo deste período, ora descrevendo Salvador e o clima que envolvia a revolta, escrevendo, por exemplo: "A população, vivamente emocionada, rodeia-os de uma simpatia respeitosa e espontânea”, como refere em 18 de agosto a propósito da chegada de soldados vindos de Monte Belo; ao mesmo tempo, avalia as missões militares anteriores com espírito crítico:

Todos os oficiais que inquiri acordam confirmando dois graves erros de que se aproveitaram habilmente os jagunços (...) O primeiro apontado completa outros que perturbam altamente a marcha da primeira coluna (...) Na investida definitiva a Canudos, a disposição geral dada ao ataque foi de tal natureza que, logo à entrada da grande aldeia, baralharam-se batalhões e brigadas, enredaram-se, anularam-se as fileiras sem ordem, atumultuadamente avançando (CUNHA, 1897).

No dia 24 de agosto, contudo, descreve vivamente a chegada dos soldados:

Ao apontar, vingando a última curva da estrada, um lúgubre c o m boio, a multidão, estacionada na gare, emudecida, vai terminando bruscamente o vozear indistinto, e olhares curiosos convergem para a
Em 1897, o Estado de S. Paulo foi

pioneiro na decisão de enviar um correspondente à Bahia para acompanhar os acontecimentos de Canudos 
locomotiva que se aproxima (...) Os feridos chegam num estado miserando (...) Dificilmente se distingue uma farda despedaçada e incolor: calças que não descem além dos joelhos, reduzidas a tangas, toras, esburacadas, rendilhadas pela miséria.

É evidente que Euclides da Cunha não se limita a observar. Ele conversa, recolhe dados, faz suas anotações e interpreta. É significativa, neste sentido, a reportagem de 27 de agosto, quando se refere à chegada de um "assustado adolescente", Agostinho, trazido prisioneiro pelo Coronel Carlos Telles à cidade. Com apenas 14 anos, "fragílimo e ágil, olhos pardos, sem brilho; cabeça chata e fronte deprimida; lábios firmes e incolores, entreabertos num leve sorriso perene, deixando perceber os dentes pequeninos e alvos" (CUNHA, 1897). Euclides registra que o rapaz "responde com vivacidade e segurança a todas as perguntas", descrevendo nitidamente as lideranças do movimento, de João Abbade, "mameluco, quase negro", a Pajeú, "hoje morto, caboclo alto e reforçado", passando por Villa Nova, Pedrão, Macambira - "velho rebarbativo e feio" - Manoel Quadrado, José Feliz, o Tramela e, enfim, Antonio Conselheiro. Quando indagado a respeito do armamento, o rapaz responde prontamente:

Antes da primeira expedição consistia em espingardas comuns, bacamartes e bestas destinadas, estas últimas, em cujo maneio são incomparáveis, não perdendo uma seta, à caçada dos mocós velozes e esquivos. Seis ou sete espingardas mais pesadas, de bala - carabinas Comblain, talvez. Depois do encontro em Uaná, e das expedições que o sucederam é que apareceram novas armas, em grande número, no arraial. Os canhões deixados pela coluna de Moreira César, cuja manejo não puderam compreender, foram depois de inutilizados a golpes de alavanca e malhos, atirados num esbarrondadeiro próximo.

Eis a síntese e a conclusão: era o próprio exército brasileiro que, ao abandonar o armamento, armava os rebeldes. Mas o que esperariam eles, afinal, quando a luta terminasse? Ainda aqui, a perspectiva dramática que a narrativa de Euclides da Cunha assume (RABELLO, 1983, p. 198), resume: "A resposta foi absolutamente inesperada. __ Salvar a alma”.

A avaliação que Olímpio de Souza Andrade faz do trabalho do repórter Euclides da Cunha é categórica: "como repórter de gênio que nobilitava extraordinariamente a grande reportagem, enviou para o seu jornal as notas completas, perfeitas, de um realismo que, uma vez ou outra, contrariava a falsa opinião que daquilo tudo fazia o país inteiro, e o seu próprio jornal" (ANDRADE, 2002, ps. 131 e 132).

Por isso, embora sendo o último a chegar ao teatro dos acontecimentos (ANDRADE, 2002, p. 159), não se pode comparar seu trabalho ao dos demais. Ele acompanhou ao vivo tudo o que pode. As-
A avaliação que Olímpio de Souza Andrade faz do trabalho do repórter Euclides da Cunha é categórica: "como repórter de gênio que nobilitava extraordinariamente a grande reportagem, enviou para o seu jornal as notas completas, perfeitas, de um realismo que, uma vez ou outra, contrariava a falsa opinião que daquilo

tudo fazia o país inteiro, e o seu próprio jornal" 
sumindo a primeira pessoa do singular, desde o primeiro boletim, é enquanto depoimento pessoal, ao mesmo tempo emocionado e crítico que ele escreve, como uma espécie de "Conrad às avessas", como registra Olímpio de Souza Andrade, para evidenciar que Euclides da Cunha, ao contrário de Joseph Conrad, também repórter, foi muito mais crítico, constituindo, por isso mesmo, obra única (MARTINS, 1977, Vol. V, p. 4), sobretudo porque o jornalista abdicou de toda e qualquer ficção (SEVCENKO, 1983, p. 131), contrariando o que a imprensa aceitara, desde logo, como uma "grande conjura monarquista, agindo nos sertões baianos" (SODRÉ, 1977, p. 307).

Foi importante, para a fidelidade dos fatos e do clima que o repórter encontrou na região, a utilização de suas cadernetas de anotações, onde registrava rapidamente as primeiras impressões e que depois consultava quando desenvolvia o texto a ser enviado. Ele não seguia uma ordem, contudo. Levava vários nos bolsos e escrevia no que lhe caísse mais à mão. Assim, num deles podemos encontrar anotações sobre as trincheiras da Gamboa, de 1893, mas também de Canudos, em 1897... (ANDRADE, 2002, p. 153), o que leva alguns de seus estudiosos a entender que as cadernetas foram verdadeiras matrizes não apenas das reportagens mas, sobretudo, do livro que ele iria publicar em 1902 e que o consagraria definitivamente.

Olímpio de Souza Andrade publicou um destes cadernos, aquele mais diretamente vinculado à campanha de Canudos (CUNHA. 1975, p. XVIII). Avalia que tais anotações permitem ao repórter não ser traído pela memória. Mais que isso, permite confrontar dados e informações, constituindo, por isso mesmo, conjunto riquíssimo do processo da escrita do jornalista e do escritor. Embora muitas vezes de dificílima leitura, pela letra miúda do escritor, exigindo, assim, diferentes consultas, a caderneta é fundamental para qualquer estudo mais profundo do trabalho de Euclides da Cunha naquele momento.

"Está claro que não ocorreria a ninguém exigir de um repórter o que ele mesmo exigia de si, principalmente de um repórter em missão itinerante como a sua, a lutar com a precariedade das informações que o levavam a corrigir-se até ao exagero", sintetiza um pesquisador (ANDRADE, 2002, p. 137). Mas é então que a competência do repórter se manifesta.

Podem-se destacar dois tipos de registros importantes nos textos enviados por Euclides da Cunha. De um lado, os depoimentos pessoalizados desde sua chegada à região. De outro, os registros que faz, profundamente emocionais, de acontecimentos que envolvem prisioneiros e que lhe permite traçar a psicologia dos jagunços, sem que tenha de classificá-los, mas, ao contrário, apenas narrando e presentificando, para o leitor distante, aquilo a que assiste e transcreve com fidelidade. Leiamos algumas passagens.
Podem-se destacar dois tipos de registros importantes nos textos enviados por Euclides da Cunha. De um lado, os depoimentos pessoalizados desde sua chegada à região. De outro, os registros que faz, profundamente emocionais, de acontecimentos que envolvem prisioneiros 
Aguardando ainda, contrafeito, a próxima partida para o sertão, percorro - desconhecido e só - como um grego antigo nas ruas de Bizâncio as velhas ruas desta grande capital, num indagar persistente acerca de suas belas tradições e observando a sua feição interessante de cidade velha chegando, intacta quase, do passado a estes dias agitados (...) Calculo com aproximação razoável em dez mil homens no mínimo, a tropa que irá combater a rebeldia no sertão (CUNHA, 1897).

O trecho é grande mas, afinal, queremos mesmo é ler Euclides da Cunha. Às vezes, o registro é vivaz, rápido, de quem está de passagem:

Aqui chegamos às cinco e meia. Alagoinhas é realmente uma boa cidade extensa e cômoda, estendendo-se sobre um solo arenoso e plano. Ruas largas, praças, imensas; não tem sequer uma viela estreita, um beco tortuoso. É talvez a melhor cidade do interior da Bahia. Convergem para ela todos os produtos das regiões em torno, imprimindo-lhe movimento comercial notável (CUNHA, 1897).

Ou então, esta outra passagem:

TANQUINHO - São dez horas da noite. Traço rapidamente estas notas sob a ramagem opulenta de um joazeiro, enquanto, em torno, todo o acampamento dorme. Tanquinho é positivamente um lugar detestável e o viajante que vence as cinco léguas que o separam de Queimadas tem a pior das decepções ante esta lúgubre tapera de duas casas abandonadas e destruídas, quase invadidas pela galhada áspera e inextricável do alecrim dos taboleiros (CUNHA, 1897).

O azedume pode dar lugar ao entusiasmo:

CANSANÇÃO - Aqui chegamos às 9 horas da manhã - esplêndida manhã! - caminhando duas léguas a partir do Tanquinho. Cansanção, felizmente, já merece o nome de povoado. Tem onze casas, algumas cobertas de telhas, e um armazém paupérrimo no qual entramos com a mesma satisfacção com que aí se penetra no Pregredior. Sentimo-nos deslumbrados ante as prateleiras toscas e desguarnecidas (CUNHA, 1897).

Até chegar ao objetivo, Monte Santo:

MONTE SANTO - Finalmente chegamos, às 9 horas da manhã, à nossa base de operações, depois de duas horas de marcha. Ninguém pode imaginar o que é Monte-Santo a três quilómetros de distância. Ereta num ligeiro socalco, ao pé de magestosa montanha, a povoação, poucos metros a cavaleiro sobre os taboleiros extensos que se estendem ao norte, está numa situação admirável (CUNHA, 1897).

Estudos em Jornalismo e Mídia - Ano VI - n. 2 pp. 131 - 147 jul./dez. 2009 
O outro aspecto, mais tenebroso, de certo modo, é, ao mesmo tempo, a contribuição maior do repórter: colhe ele, ao vivo, as cenas que ocorrem no dia a dia, especialmente o interrogatório de prisioneiros e o seu comportamento. Ou episódios de valentia e absoluta temeridade dos jagunços. É o caso, por exemplo, do despacho de 18 de agosto, publicado em 25 de agosto (apenas uma semana de intervalo!):

Um Episódio da Luta - Em dias de junho ultimo um dos filhos de Macumbira, adolescente de quinze anos abeirou-se do rude chefe sertanejo: - Pai, quero destruir a matadeira. (Sob tal denominação indicam os jagunços o canhão Krupp, 32, que tem feito entre eles estragos consideráveis). Sinistro cabecilha, espécie grosseira de Imanus acobreado e bronco, fitou-o impassível: - Consulta o Conselheiro - e vai. E o rapaz seguiu acompanhado de onze companheiros atrevidos (....) O exército repousava... Nisto despontam, emergindo cautos, à borda do moto rasteiro e trançado de árvores baixas a esgalhadas, na clareira em que estaciona a artilheria, doze postas espantados - olhares rupidos a perscrutando todos os pontos, - doze rostos apenas de homens ainda mergulhados, de rastos, no seio trançado das macambiras. E surgem lentamente; ninguem os vê; ninguem os pode ver; - dá lhes na costas, numa indiferença soberana, o exército que repousa (...) Formam-se rapidamente os batalhões; num momento os atacantes ousados vêm-se, presos, num círculo intransponível de baionetas e caem sob os golpes e sob as balas. Um apenas se salva, golpeado, baleando, saltando, correndo, rolando, intangível entre os soldados, atravessando, uma rêde de balas, vingando os pontos das baionetas, caindo em cheio nas catingas que atravessa velozmente e despenhando-se, livre afinal, alcandorado sobre abismos, pelos pendores aprumados da montanha... Estas e outras histórias, contamnas, aqui, os soldados, colaboradores inconscientes das lendas que envolverão mais tarde esta campanha crudelíssima (CUNHA, 1897).

Ou então, este outro relato:

Escrevo rapidamente estas linhas, no meio do tumulto quase, enquanto a fuzilaria intensa suleia os ares a cem metros de distância. Acabam de chegar alguns prisioneiros. O primeiro é um ente sinistro ; um estilhaço de granada transformou-lhe o olho esquerdo numa chaga hedionda, de onde goteja um sangue enegrecido; baixo e de compleição robusta, responde tortuosamente a todas as perguntas (...) Nada revela. Chegam mais duas prisioneiras, mãe e filha; a primeira esquelética e esquálida - repugnante, a segunda mais forte e de feições atraentes. Evitam igualmente tanto quanto possível responder ao interrogatório do general. A filha apenas revela: - Villa-Nova esta noite lascou o pé no caminho (2) e há um lote de dias (3) que um des-
A contribuição maior do repórter: colhe ele, ao vivo, as cenas que ocorrem no dia a dia, especialmente o interrogatório de prisioneiros e o seu comportamento. Ou episódios de valentia e absoluta temeridade dos jagunços 
potismo de gente (4) tem abancado (5) para o curube o Caipan. Está com muitos dias que há fome em Belo Monte. A velha nada sabe, evita todas as respostas e nada pode dizer sobre o número de inimigos porque só sabe contar até quarenta! Morreu-lhe o marido há meia hora; era um baiano truculento; expirou atravessado pelas balas, cinco minutos depois de haver morto com um tiro de bacamarte ao alferes do $24^{\circ}$ Pedro Simões Pontes e murmurou com um sorriso sinistro ao expirar: - Estou contente! Ao menos matei um! Viva o Bom Jesus! (CUNHA, 1897).

No relato seguinte, mais episódios envolvem prisioneiros e dão conta de sua fidelidade a Antonio Conselheiro:

Mulheres aprisionadas na ocasião em que os maridos caíam mortos na refrega e a prole espavorida desaparecia na fuga, aqui têm chegado (...) Uma delas acaba de ser conduzida à presença do general. Estatura pequena, rosto trigueiro, cabelos em desalinho, lábios finos e brancos, rugados aos cantos por um riso doloroso, olhos vesgos, cintilantes; trás ao peito, posta na abertura da camisa, a mão direita, ferida por um golpe de sabre. - Onde está teu marido? - No céu. - Que queres dizer com isto? - Meu marido morreu. E o olhar correu rápido o fulgurante sobre os circunstantes sem se fitar em ninguém (...) - Há muita gente aí, em Canudos? - E eu sei? ... eu não vivo navegando na casa dos outros. Está com muitos dias que ninguém sabe por via das peças. E eu sei contar? Só conto até quarenta e rola o tempo p'ra contar a gente de Belo Monte... - O Conselheiro tem recebido algum auxílio de fora, munições, armas?... - E eu sei? Mas porém em Belo Monte não manca arma nem gente p'ra brigar. - Onde estava seu marido quando foi morto? Esta pergunta foi feita por mim e em má hora a fiz. Fulminou-me com o olhar. - E eu sei? (...) E eu sei?... Este e eu sei? É o inicio obrigado das respostas de todos; surge espontâneamente, infalívelmente, numa toada monótona, encimando todos os períodos, cortando persistentemente todas as frases. - Fugiram muitos jagunços hoje, no combate? - E eu sei? meu marido foi morto por um lote de soldados quando saía; o mesmo tiro quebrou o braço do meu filho de colo... Fiquei estatalada, não vi nada... este sangue aqui na minha manga é do meu filho, o que eu queria era ficar lá também, morta... (CUNHA, 1897).

O repórter revela sentimentos pessoais e os transmite ao leitor, quando adentra a cruel realidade de Monte Santo:

O interior das casas assusta...Compreende-se que haja povos vivendo ainda, felizes e rudes, nas anfratuosidades fundas das rochas (...) mas não se compreende a vida dentro dessas furnas escuras e sem ar, tendo como única abertura, às vezes, a porta estreita da entrada e cobertas por um teto massiço e impenetrável de argila sobre folhas 
de icó! Quando o olhar do observador se acomoda afinal à penumbra que reina no interior percebe uma mobília que é a de todas as casas quase: um banco grande e grosseiro (uma táboa sobre quatro pés não torneados ); dois ou três banquinhos; redes de cruá; dois ou três baús de cedro de três palmos sobre dois. É toda a mobília. Não há camas; não há mesas, de um modo geral (CUNHA, 1897).

E chega, então, o final, assim resumido pelo repórter:

A artilheria fez estragos incalculáveis nas pequenas casas, repletas todas. Penetrando pelos tetos e pelas paredes as granadas explodiam nos quartos minúsculos despedaçando homens, mulheres e crianças sobre os quais descia, as vezes o pesado teto de argila, pesadamente, como a lagem de um túmulo, completando o estrago. Parece, porém, que os mal feridos mesmo sofreiavam os brados da agonia e os próprios tímidos evitavam a fuga, tal o silêncio, tal a quietude soberana e estranha, que pairavam sobre as ruínas fumegantes, quando, às 6 e 48 minutos, cessou o bombardeio (...) Nesse momento passou-se um fato extraordinário e inesperado em que pese aos números exemplos de heróica selvatiqueza revelada pelo jagunço. De todas as casas, há poucos minutos fulminadas, irrompendo de todas as frinchas das paredes e dos tetos, saindo de todos os pontos explodiu uma fuzilaria imensa, retumbante, mortífera e formidável, de armas numerosas rápida e simultaneamente disparadas - e sobre os batalhões assaltantes refluiu a réplica tremenda de uma saraivada, impenetrável, de balas! (...) Eu estava a cerca de 200 metros apenas da praça, no quartel general do general Barbosa. Desci rapidamente a encosta e entrei na zona do combate. Não gastei dois minutos na travessia (CUNHA, 1897).

Euclides da Cunha, no último artigo enviado, a 25 de outubro, e publicado no dia imediatamente após, afirma, com sinceridade: "Isto é o depoimento de uma testemunha pouco afeiçoada à lisonja banal e inútil”.

\section{Do jornalismo para a literatura, mas sempre jornalismo}

E mais não diz, porque, segundo muitos de seus estudiosos, ao regressar, já imaginara escrever um livro a respeito do tema (RABELLO, 1983, p. 140). Mesmo antes de partir, reunira material fornecido por Teodoro Sampaio. Também conversaria muito com Manuel Benício, que acabaria por publicar seu livro três anos antes de Euclides, pois que sua primeira edição é de 1899 (ARAÚJO apud BENICIO, 1997, p. IX). Por isso, foi-lhe importante, ao regressar, poder ficar no interior do estado de São Paulo, onde podia se dedicar com maior afinco a seu projeto. Mas enfrentava, evidentemente, a dificuldade de publicá-lo, diante das dimensões que alcançaria o trabalho. Assim, termina por financiar a primeira edição, entregue
Euclides da Cunha,

no último artigo enviado, a 25 de outubro, e publicado no dia imediatamente após, afirma, com sinceridade: "Isto é o depoimento de uma testemunha pouco afeiçoada

à lisonja banal e inútil" 
a Editora Laemert, fato que não o imuniza contra a expectativa e a tensão do lançamento. O exame de sua correspondência bem evidencia tal situação (VENANCIO FILHO, 1997).

A primeira edição sai com muitas gralhas, o que o incomoda. Mas esgota-se rapidamente, e para a segunda edição, ainda a cargo da Laemmert, Euclides busca corrigir os defeitos do livro (VENANCIO FILHO, 1997, ps. 78,83 e 100).

Também o escritor Afonso Arinos, sob o pseudônimo de Olívio Barros, se adiantara a Euclides, publicando em fascículos, no O Comércio de São Paulo, de que era redator-chefe, a partir de 24 de outubro de 1897, o folhetim Os jagunços que logo seria transformado em livro (GALVÃO, 1994, p. 105). Mas seria o livro de Euclides da Cunha que permaneceria como um dos depoimentos mais trágicos, mais definitivos e de mais eficiente denúncia sobre as condições de marginalização experimentada por nossos interioranos. Como avalia Franklin de Oliveira, trata-se de um "monumento da cultura ibero-americana", porque, "antes de pensar no gênero, pensou na forma. Esta lhe deve ter parecido muito mais importante do que aquele, dado o alvo que buscava atingir. Esse alvo era a Nação brasileira. O Brasil de seu tempo era um país submerso em verbalismo" (OLIVEIRA, 1983, ps. 13 e 48). E lançando mão da avaliação de José Maria Belo, encerra: "[tratase de] um livro grave, onde se agitam alguns problemas capitais da nossa vida política e social" (BELO, 1956).

Apesar do sucesso e da repercussão quase imediatos do livro, ainda hoje, mais de um século passado, continuamos nos perguntando o que é exatamente Os sertões, o que o escritor queria com essa obra? Por que a escreveu? Para mim, é a perspectiva do jornalismo que oferece as melhores respostas. A leitura dessas reportagens nos permite verificar práticas claramente jornalísticas em Euclides da Cunha: a) levantamento antecipado de dados, a partir do momento em que recebe a pauta para a viagem; b) visita e deambulação pelos lugares, na melhor prática da reportagem contemporânea; c) fala com todo o tipo de fonte, e não apenas com as fontes oficiais, estabelecendo, assim, equilíbrio quanto aos pontos de vista apresentados; d) entrevista as pessoas mais variadas e transcreve tais diálogos, numa prática de entrevista extremamente moderna e eficiente, porque profusamente dramática; e) utilização da primeira pessoa do singular, com o que enfatiza o depoimento que suas reportagens traduzem; f) como bem registrou Walnice Nogueira Galvão, e pode-se aplicar sobretudo a Euclides da Cunha, seu trabalho é grande e se tornou imortal porque foi feito no calor da hora, É testemunho, naquela linha que pouco depois John Reed realizaria com o mundialmente reconhecido Dez dias que abalaram o mundo, é o relato do aqui e agora, melhor característica do jornalismo, trazendo o distante para o perto e o passado para o presente, sempre atualizado.
Como avalia Franklin de Oliveira, trata-se [Os Sertões]de um "monumento da cultura iberoamericana", porque, "antes de pensar no gênero, pensou na forma. Esta lhe deve ter parecido muito mais importante do que aquele, dado o alvo que buscava atingir. Esse alvo era a Nação brasileira. 


\section{Referências}

ANDRADE, Olímpio de Souza. História e interpretação de "Os sertões". Rio de Janeiro, Academia Brasileira de Letras. 2002.

BARROS, Frederico Ozanam Pessoa de. Euclides da Cunha. São Paulo, Abril Cultural. 1982, Coleção Literatura comentada.

BELO, José Maria. História da república - 1889-1954. São Paulo, Nacional. 1956.

BENICIO, Manoel. O rei dos jagunços. Rio de Janeiro, Fundação Getúlio Vargas/Jornal do Commercio, 1997.

BULHÕES, Marcelo. Jornalismo e literatura em convergência. São Paulo, Ática. 2007.

CUNHA, Euclides da. Caderneta de campo. São Paulo/Brasília, Cultrix/MEC. 1975, edição de Olímpio de Souza Andrade.

CUNHA, Euclides da. Os sertões. São Paulo, Brasiliense/Secretaria de Estado da Cultura. 1985. Organização de Walnice Nogueira Galvão.

FERREIRA, Jorge et DELGADO, Lucília de Almeida Neves (Org.). O Brasil republicano - O tempo do liberalismo excludente. Rio de Janeiro, Civilização Brasileira. 2006, Vol. 1.

GALVÃO, Walnice Nogueira. No calor da hora. São Paulo, Ática. 1994.

INSTITUTO MOREIRA SALLES. Euclides da Cunha. São Paulo. 2002, Vols. 13 e 14 dos "Cadernos de Literatura Brasileira".

MARTINS, Wilson. História da inteligência brasileira - 1897-1914. São Paulo, Cultrix/EDUSP. 1977/1978. Vol. V.

MELO, José Marques de et QUEIROZ, Adolpho. Identidade da imprensa brasileira no final de século. São Paulo, UMESP/Cátedra UNESCO. 1998.

MOURA,Clóvis. Introdução ao pensamento de Euclides da Cunha. Rio de Janeiro, Civilização Brasileira. 1964.

OLIVEIRA, Franklin de. A espada e a letra. Rio de Janeiro, Paz e Terra. 1983. RABELLO, Sylvio. Euclides da Cunha. Rio de Janeiro/Brasília, Civilização Brasileira/Instituto Nacional do Livro. 1983.

SARMATZ, Leandro. A república em perigo: Uma análise do capítulo "A quarta expedição”, d'Os sertões, e seu contexto político. Porto Alegre, PUCRS. Mimeo. 1995.

SCHWARTZ, Roberto (Org.). Os pobres na literatura brasileira. São Paulo, Brasiliense. 1983.

SEVCENKO, Nicolau. Literatura como missão. São Paulo, Brasiliense. 1983.

SODRÉ, Nelson Werneck. História da imprensa no Brasil. São Paulo, Graal. 1977.

VENÂNCIO FILHO, Francisco. Euclydes da Cunha a seus amigos. São Paulo, Nacional. 1938.

www.academia.org.br/abl_minisites/cgi/cgilua.exe/sys/start.htm? 